\title{
First-Trimester Reference Intervals for Thyroid Function Testing among Women Screened at a Tertiary Care Hospital in India
}

\author{
Rachita Nanda ${ }^{1}$ Prasanta Kumar Nayak ${ }^{2}$ Suprava Patel ${ }^{1}$ Eli Mohapatra ${ }^{1}$ Sarita Agrawal ${ }^{2}$ \\ ${ }^{1}$ Department of Biochemistry, All India Institute of Medical Sciences, \\ Raipur, Chhattisgarh, India \\ 2 Department of Obstetrics and Gynecology, All India Institute of \\ Address for correspondence Rachita Nanda, MBBS, MD, Department \\ of Biochemistry, All India Institute of Medical Sciences, GE Road, \\ Tatibandh, Raipur, Chhattisgarh, 492099, India \\ Medical Sciences, Raipur, Chhattisgarh, India \\ (e-mail: dr.rachitananda@gmail.com).
}

J Lab Physicians 2022;14:183-189.

\begin{abstract}
Keywords

- thyroid-stimulating hormone

- thyroxine

- reference range

- pregnancy

- multiple of median
\end{abstract}

Objectives Due to differences in the method of assay and population-specific factors, each laboratory needs to establish its own gestation-specific reference intervals (GRIs) for thyroid hormones.

Materials and Methods Three-hundred forty-one women with less than 14 weeks gestation were screened at a tertiary care hospital in Chhattisgarh, India. Serum levels of thyroid-stimulating hormone (TSH), free thyroxine (fT4), and thyroid peroxidase antibody (anti-TPO) were measured using an ADVIA Centaur XP immunoassay.

GRIs (2.5th and 97.5th percentiles) were determined for TSH and fT4. TSH and fT4 concentrations were converted to multiples of the median (MoM) values. Effect of maternal age, gestational age, and maternal weight was analyzed.

Statistical Analysis Quantitative variables were expressed as means and standard deviations (SD), and qualitative variables were expressed as frequencies and percentages. Normality of the data was checked using the Kolmogorov-Smirnov test. Values that were normally distributed were expressed only as means and SD. Those that were not normally distributed were expressed as medians and interquartile range. For all statistical analysis, $p<0.05$ was considered as statistically significant.

Results First-trimester GRI was 0.245 to $4.971 \mathrm{mIU} / \mathrm{L}$ for TSH, 10.2 to $18.9 \mathrm{pmol} / \mathrm{L}$ for fT4, and 27.0 to $56.89 \mathrm{kIU} / \mathrm{L}$ for anti-TPO. There was no significant difference in the mean serum TSH $(p=0.920)$, fT4 $(p=0.714)$, or anti-TPO $(p=0.754)$ values among women in 4 to 7 th week and 7 to 14 th week of gestation. The 1 st and 99 th centile MoMs were 0.03 and 4.09 for TSH and 0.66 and 1.39 for fT4. There was a significant positive correlation between the maternal weight and TSH MoM values $(p=0.027, r=0.120)$. Conclusion These laboratory- and first-trimester-specific GRI for TSH and fT4 shall help in proper diagnosis and treatment of subclinical thyroid dysfunctions. TSH and fT4 MoM values can be used to indicate high or low values in a quantitative manner independent of the reference ranges and may be used by other laboratories. published online

November 2, 2021
DOI https://doi.org/

$10.1055 / \mathrm{s}-0041-1736520$. ISSN 0974-2727. (c) 2021. The Indian Association of Laboratory Physicians. All rights reserved.

This is an open access article published by Thieme under the terms of the Creative Commons Attribution-NonDerivative-NonCommercial-License, permitting copying and reproduction so long as the original work is given appropriate credit. Contents may not be used for commercial purposes, or adapted, remixed, transformed or built upon. (https://creativecommons.org/ licenses/by-nc-nd/4.0/)

Thieme Medical and Scientific Publishers Pvt. Ltd., A-12, 2nd Floor, Sector 2, Noida-201301 UP, India 


\section{Introduction}

Thyroid hormones (TH) are crucial for embryogenesis and fetal development. During the first half of the pregnancy, they are sourced entirely from the $\mathrm{TH}$ circulating in the maternal blood. ${ }^{1}$ Thyroid dysfunction during pregnancy increases the risk of complications such as pregnancy loss, premature delivery, gestational diabetes, gestational hypertension, low newborn birth weight, and impaired neuropsychological development. $^{2}$

During pregnancy, the increased demand for $\mathrm{TH}$ for fetal development, increased concentration of thyroxine-binding globulin due to increase in estrogen levels, and inactivation of TH by placental iodothyronine deiodinase type 3 necessitate the increased production of maternal $\mathrm{TH} .{ }^{1}$ The pregnancy hormone, $\beta$-human chorionic gonadotropin, is a weak thyroid-stimulating hormone (TSH) receptor agonist. It also stimulates the thyroid gland to compensate for the increased degradation of TH. ${ }^{1}$ TSH level decreases and the free thyroxine (fT4) level in the maternal blood increases. Hence, there is a need for determining gestation-specific reference intervals (GRIs) for normal thyroid function. This may help to identify women who can potentially benefit from timely treatment.

Studies done at a few centers cannot be extrapolated to all centers globally due to differences in method of assay as well as population-specific factors such as ethnicity, body mass index (BMI), and iodine intake. The reference intervals for thyroid function tests in the same woman also vary from one trimester to another. The International Federation of Clinical Chemistry (IFCC), the International Committee for Standardization in Hematology, the Endocrine Society, the European Thyroid Association, and the American Thyroid Association (ATA) advise every center to determine their own population-based trimester-specific GRIs. ${ }^{3-6}$

Initial recommendations by ATA and the European Endocrinology Society had set the TSH reference limits of 0.1 to $2.5 \mathrm{mIU} / \mathrm{L}$ for the first trimester. ${ }^{7}$ The ATA guidelines revised in 2017 recommend that pregnancy-specific and laboratoryspecific reference ranges for TSH and fT4 should be calculated. If that is not possible, a reference range can be used from the literature that is derived from a population with similar ethnicity, BMI, iodine status, etc. ${ }^{8}$ If both are not possible, ATA recommends the first-trimester upper cutoff limit $0.5 \mathrm{mIU} / \mathrm{L}$ less than the pre-pregnancy TSH value. If the pre-pregnancy value is unavailable, the upper limit is taken to be $4.0 \mathrm{mIU} / \mathrm{L}$. 7,8

The definition of a thyroid disorder tends to be dependent on the TH level because of which the top $2.5 \%$ and the bottom $2.5 \%$ of people are believed to have thyroid dysfunction. This can be misleading and lead to unnecessary treatment for many people. Expressing TH levels as multiple of median (MoM) values can allow for interlaboratory assay variations, gestational age, and other factors that may affect the marker levels. ${ }^{9}$ To unitize laboratory reports and aid in uniform interpretation of results, MoM values may be incorporated in reporting. MoM measures how far the result deviates from the median. This value is the ratio of the patient's result and the median result appropriate for the gestational period.
Maturation of the fetal thyroid function involves proper functional development of the hypothalamus, pituitary gland, and the thyroid gland. This process is more or less complete by the 12 th to 14 th week of gestation. ${ }^{10}$ After the 14 th week of gestation, there may be irreversible effect on the fetal brain development due to lack of adequate TH in the maternal blood.

Some studies show that the median TSH in early first trimester $(4-6$ weeks) is significantly higher $(p<0.001)$ than that in the late first trimester (7-12 weeks). ${ }^{11}$ The Polish Society of Endocrinology recommends universal thyroid screening of all women either preconception or at their first antenatal visit (4-8 weeks). ${ }^{12}$ However, the current ATA guidelines cite unclear evidence in support of universal thyroid screening. They strongly recommend clinical evaluation of all patients, who seek pregnancy or are newly pregnant, for identifying risk factors of thyroid disorders. ${ }^{13}$ Only those with risk factors for thyroid disorders are then tested for thyroid function.

In this study, we determined the first-trimester GRIs of TH for pregnant women in Chhattisgarh state in India. We studied if the GRIs changed depending on whether the $\mathrm{TH}$ levels were determined in the early weeks (4-7th week) or the late weeks (7-14th week) of the first trimester. We also calculated the MoM values of TSH and fT4.

\section{Materials and Methods}

\section{Subjects}

\section{Study Design and Setting}

This cross-sectional study was conducted at a tertiary care and medical college facility in Chhattisgarh, India. The institutional ethics committee approved the study protocol and due written consent was obtained from the study participants before including them in the study.

\section{Participants}

Healthy pregnant women of more than 18 years of age, with uncomplicated single intrauterine gestations in first trimester, attending the Out Patient Department of Obstetrics and Gynecology, for antenatal care between June 2017 and September 2019, were consecutively enrolled for the study. The cutoff gestational age for the first trimester was considered to be up to 14 completed weeks, that is, 98 days. ${ }^{14}$ Selected subjects were assessed by the obstetrician for demographic and clinical details. Gestational age was calculated from the first day of last menstrual period (LMP). If LMP was unknown, gestational age was determined by ultrasonographic scan. Participants in early first trimester (4th-7th week) were categorized in Group A and those in late first trimester (7th-14th week) in Group B.

Women with one or more of the following were excluded from the study: (i) history and signs or symptoms of thyroid dysfunction; (ii) past or present history of intake of antithyroid drugs or thyroxine; (iii) any chronic medical disease such as hypertension, diabetes mellitus or presence of any other autoimmune disorders; (iv) history of recurrent miscarriages; (v) multiple gestations; (vi) positive thyroid 
peroxidase antibody (anti-TPO) status indicated by anti-TPO levels $>60 \mathrm{kIU} / \mathrm{L}$; (vii) $\mathrm{TSH}>10 \mathrm{mIU} / \mathrm{mL}$; or (viii) urinary iodine levels of $\leq 150 \mu \mathrm{g} / \mathrm{L}$.

\section{Sample Size}

Because of the high interindividual variability and skewness for TSH and also to some extent fT4, we followed the recommendation of Clinical and Laboratory Standards Institute and IFCC, and took around 400 individual measurements for calculation of the reference interval. ${ }^{15,16}$

\section{Methods}

Fasting venous blood $(5 \mathrm{~mL})$ was collected. Serum was separated and stored at $-20^{\circ} \mathrm{C}$ until analysis of TSH, fT4, and anti-TPO, by chemiluminescence technique. We used commercially available kits from Siemens HealthCare Diagnostics, United States, with Siemens ADVIA Centaur XP immunoassay analyzer.

The ADVIA Centaur TSH3-Ultra assay is a third-generation assay that measures TSH concentrations from 0.008 to $150 \mu \mathrm{IU} / \mathrm{mL}(\mathrm{mIU} / \mathrm{L})$. As per the manufacturer's kit insert, the precision of TSH for within run coefficient of variation (CV\%) and run to run CV\% was (1.93-4.69) and (1.2-6.64), respectively. fT4assay is a competitive immunoassay, with sensitivity and assay range of 0.1 to $12.0 \mathrm{ng} / \mathrm{dL}$ (1.3-155 pmol/L). The within run $\mathrm{CV} \%$ ranged from 2.23 to 3.33 and run to run CV\% from 2.33 to 4.00 . The ADVIA Centaur anti-TPO assay is a competitive immunoassay with sensitivity and assay range of 15 to $1,300 \mathrm{U} / \mathrm{mL}$ or $\mathrm{kIU} / \mathrm{L}$ of within run CV\% (1.3-6.8) and run to run CV\% (2.8-3.4).

Spot urine sample $(5 \mathrm{~mL})$ was collected and stored at $-20^{\circ} \mathrm{C}$. Urinary iodine concentration was determined by the wet digestion method on the basis of Sandell-Kolthoff reaction. $^{17}$

\section{Statistical Analysis}

All statistical analysis was done by using SPSS trial version and in MS-Excel 2007. Quantitative variables were expressed as means and standard deviations and qualitative variables were expressed as frequencies and percentages. Normality of the data was checked by using Kolmogorov-Smirnov test. Values that were normally distributed were expressed only as means and standard deviation. Those that were not normally distributed were expressed as medians and interquartile range. Analysis of variance was used as a test of difference of more than two means and linear regression analysis was used for finding the correlation. Chi-squared test was used for examining the categorical variables. For all statistical analysis, $p<0.05$ was considered as statistically significant.

The 2.5th and 97.5 th percentiles for TSH, fT4, and anti-TPO were determined in the first trimester to find the reference range for each of these measures. MoM values were calculated for TSH and fT4.

\section{Results}

\section{Study Population}

A total of 412 consecutive women in their first trimester were screened for the study. Nine of them were either on $\mathrm{TH}$
Table 1 Descriptive characteristics of the study population $(n=341)$

\begin{tabular}{|c|c|}
\hline Parameter & Value \\
\hline Median age in years (range) & $25(18-42)$ \\
\hline Mean BMI in $\mathrm{kg} / \mathrm{m}^{2} \pm \mathrm{SD}$ (range) & $\begin{array}{l}20.69 \pm 3.474 \\
(13.01-36.20) \\
\end{array}$ \\
\hline \multicolumn{2}{|l|}{ Obstetric history } \\
\hline $\begin{array}{l}\text { Mean gestational age } \\
\text { (in days) } \pm \text { SD at } \\
\text { presentation (range) }\end{array}$ & $63.19 \pm 16.768(31-98)$ \\
\hline $\begin{array}{l}\text { Number of women in } \\
4-7 \text { weeks of gestation (\%) }\end{array}$ & $86(25.2)$ \\
\hline $\begin{array}{l}\text { Number of women in } \\
7-14 \text { weeks of gestation (\%) }\end{array}$ & $255(74.8)$ \\
\hline \multicolumn{2}{|l|}{ Gravida (\%) } \\
\hline 1 & $150(44.0)$ \\
\hline 2 & $125(36.6)$ \\
\hline 3 & $51(15.0)$ \\
\hline 4 & $12(3.5)$ \\
\hline 5 & $3(0.9)$ \\
\hline \multicolumn{2}{|l|}{ Para (\%) } \\
\hline 0 & $175(51.3)$ \\
\hline 1 & $131(38.4)$ \\
\hline 2 & $34(10.0)$ \\
\hline 3 & $1(0.3)$ \\
\hline \multicolumn{2}{|l|}{ Living (\%) } \\
\hline 0 & $192(56.3)$ \\
\hline 1 & $129(37.8)$ \\
\hline 2 & $19(5.6)$ \\
\hline 3 & $1(0.3)$ \\
\hline \multicolumn{2}{|l|}{ Abortion (\%) } \\
\hline 0 & $255(74.8)$ \\
\hline 1 & $70(20.5)$ \\
\hline 2 & $12(3.5)$ \\
\hline 3 & $4(1.2)$ \\
\hline
\end{tabular}

Abbreviations: BMI, body mass index; SD, standard deviation.

medication or had hypothyroid blood profile, one had a twin pregnancy, and one was diagnosed with sickle-cell trait. Seven women had a TSH $>10 \mathrm{mIU} / \mathrm{mL}$ and 56 had antiTPO $>60 \mathrm{kIU} / \mathrm{L}$. After excluding these patients, the data of 341 women was analyzed (-Table 1 ).

The median age was 25 years (range: $18-42$ years) and the mean BMI was $20.69 \mathrm{~kg} / \mathrm{m}^{2}$ (range: $13.01-36.20 \mathrm{~kg} / \mathrm{m}^{2}$ ). Of the 341 women analyzed, 150 (44.0\%) were primigravida and 175 (51.3\%) were nulliparous.

\section{Reference Values for Thyroid Hormones and Thyroid Peroxidase Antibody}

The mean \pm standard deviation, median and GRIs for TSH, fT4, and anti-TPO during the first trimester are shown 
Table 2 TSH, fT4, and anti-TPO values in first trimester $(n=341)$

\begin{tabular}{|l|l|l|l|}
\hline Parameters & Mean \pm SD (range) & Median & Reference range (2.5th-97.5th percentile) \\
\hline TSH $(\mathrm{mlU} / \mathrm{L})$ & $2.04 \pm 1.30(0.02-10.08)$ & 1.82 & $0.25-4.97$ \\
\hline fT4 $(\mathrm{pmol} / \mathrm{L})$ & $14.5 \pm 2.02(9.3-21.0)$ & 14.4 & $10.2-18.8$ \\
\hline Anti-TPO $(\mathrm{kIU} / \mathrm{L})$ & $38.23 \pm 9.293(27-60)$ & 36.60 & $27.0-56.89$ \\
\hline
\end{tabular}

Abbreviations: Anti-TPO, antibody against thyroid peroxidase; fT4, free thyroxine; SD, standard deviation; TSH, thyroid stimulating hormone. $1 \mathrm{pmol} / \mathrm{L}=0.078 \mathrm{ng} / \mathrm{dL} ; 1 \mathrm{kIU} / \mathrm{L}=1 \mathrm{mIU} / \mathrm{L}$.

in - Table 2. According to our study, in the first trimester, the reference interval of serum TSH was 0.25 to $4.97 \mathrm{mIU} / \mathrm{L}$ and of serum fT4 was 10.2 to $18.9 \mathrm{pmol} / \mathrm{L}$. The reference interval for anti-TPO was 27.0 to $56.89 \mathrm{kIU} / \mathrm{L}$.

There was no significant difference in the mean serum TSH, fT4, or anti-TPO values among women in Group A and Group B ( $p=0.920,0.714$, and 0.754 , respectively, - Table 3 ). The median values and the reference ranges of TSH, fT4, or anti-TPO were similar between the two groups ( - Table 3 ).

There was a significant $(r=-0.189, p<0.001)$ inverse correlation between TSH and fT4 levels and a significant $(r=$ $0.167, p=0.002$ ) positive correlation between urinary iodide and anti-TPO levels. There was no statistically significant difference in either serum TSH level $(p=0.265, r=0.164$, - Supplementary Fig. S1A) or serum fT4 ( $p=0.059, r=0.176$, - Supplementary Fig. S1B) level across increasing gestational age in the first trimester.

- Table 4 shows selected centiles of TSH and fT4 in conventional units and their MoM values. MoM values for 1 st and 99th centiles for TSH were 0.03 and 4.09 , respectively. Corresponding values for fT 4 were 0.66 and 1.39 , respectively.

We found a significant positive correlation between the maternal weight and TSH MoM values $(p=0.027, r=0.120)$ but not between maternal age and TSH MoM values $(p=0.164, r=0.076)$ (-Supplementary Figs. S2 and $\mathbf{S 3})$. In contrast, there was no significant correlation between maternal weight and fT4 MoM values ( $p=0.749, r=-0.017)$ and between maternal age and fT4 MoM values $(p=0.176$, $r=0.073)$ (-Supplementary Figs. $\mathbf{S 2}$ and $\mathbf{S 3}$ ).

\section{Discussion}

In our study, in the first trimester, the GRI of serum TSH was 0.25 to $4.97 \mathrm{mIU} / \mathrm{L}$. The upper limit was higher than that mentioned in ATA guidelines as well as obtained from several other studies ( - Table 5 ). This may be due to the difference in study design, sample size used, ethnicity, region, and/or assay method.

Low maternal TSH that is still detectable is unlikely to be of clinical significance. However, since the normal upper limit of maternal TSH in our study population is higher than that set by ATA guidelines, the use of the GRI of ATA for pregnant women attending our institute could lead to misdiagnosis and mistreatment in many women. Overtreatment with $\mathrm{TH}$ can hinder proper fetal brain development and increase the risk of child mental health disorder, ADHD, and autism spectrum disorder. ${ }^{18}$ Therefore, we needed to set our own institutional GRI.

Table 3 Comparison of mean, median, and reference range values of serum TSH, fT4, and anti-TPO among pregnant women in first trimester

\begin{tabular}{|l|l|l|l|}
\hline & Mean & Median & \multicolumn{1}{|l|}{$\begin{array}{l}\text { Reference range } \\
\text { (2.5th-97.5th percentile) }\end{array}$} \\
\hline \multicolumn{5}{|l|}{ Serum TSH level in mIU/L } & 1.82 & $0.33-5.72$ \\
\hline Group A & $2.01 \pm 1.42$ & 1.81 & $0.18-4.98$ \\
\hline Group B & $2.04 \pm 1.33$ & \multicolumn{2}{l|}{} \\
\hline$p$-Value & 0.920 & 14.4 & $10.2-18.4$ \\
\hline Serum fT4 level in pmol/L & $14.5 \pm 2.034$ & 14.4 & $9.8-19.1$ \\
\hline Group A & $14.5 \pm 2.021$ & & \\
\hline Group B & 0.714 & \multicolumn{3}{l|}{} \\
\hline$p$-Value & $38.33 \pm 9.96$ & 35.1 & $27-57.54$ \\
\hline Serum anti-TPO levels in kIU/L & 36.7 & $27-56.8$ \\
\hline Group A & $37.80 \pm 9.23$ & & \\
\hline Group B & 0.754 & \\
\hline$p$-Value &
\end{tabular}

Abbreviations: Anti-TPO, antibody against thyroid peroxidase; fT4, free thyroxine; TSH, thyroid stimulating hormone.

Group A $(n=86)$ included women in 4th to 7th week of gestation. Group B $(n=255)$ included women in 7th to 14th week of gestation.

$1 \mathrm{pmol} / \mathrm{L}=0.078 \mathrm{ng} / \mathrm{dL} ; 1 \mathrm{kIU} / \mathrm{L}=1 \mathrm{mIU} / \mathrm{L}$. 
Table 4 Selected centiles of TSH and fT4 in conventional units and their MoM values

\begin{tabular}{|l|l|l|l|l|}
\hline Centile & TSH in mIU/L & TSH MoM & fT4 in pmol/L & fT4 MoM \\
\hline 1 & 0.06 & 0.03 & 9.525 & 0.66 \\
\hline 2 & 0.203 & 0.11 & 10.01 & 0.69 \\
\hline 2.5 & 0.245 & 0.13 & 10.17 & 0.71 \\
\hline 5 & 0.416 & 0.23 & 10.97 & 0.76 \\
\hline 10 & 0.56 & 0.31 & 11.97 & 0.83 \\
\hline 50 & 1.82 & 1 & 14.42 & 1 \\
\hline 90 & 3.78 & 2.08 & 17.12 & 1.19 \\
\hline 95 & 4.309 & 2.37 & 17.76 & 1.23 \\
\hline 97.5 & 4.971 & 2.73 & 18.83 & 1.31 \\
\hline 98 & 5.978 & 3.28 & 19.19 & 1.33 \\
\hline 99 & 7.446 & 4.09 & 20.03 & 1.39 \\
\hline
\end{tabular}

Abbreviations: fT4, free thyroxine; MoM, multiples of median; TSH, thyroid stimulating hormone.

$1 \mathrm{pmol} / \mathrm{L}=0.078 \mathrm{ng} / \mathrm{dL} ; 1 \mathrm{kIU} / \mathrm{L}=1 \mathrm{mIU} / \mathrm{L}$.

The definition of thyroid dysfunction is also dependent on the fT4 concentration. In our study, serum fT4 reference range during the first trimester was from 10.2 to $18.8 \mathrm{pmol} / \mathrm{L}$. Rajput et $\mathrm{al}^{19}$ reported first trimester serum fT4 range as 0.88 to $1.78 \mathrm{ng} / \mathrm{mL}$ that is equivalent $1,132.560$ to $2,290.860 \mathrm{pmol} / \mathrm{L}$. These values are almost 100 times more than ours and most other studies ( - Table 5 ). We wonder if there was an error in the use of units by Rajput et al. ${ }^{19}$ They report their fT4 values in $\mathrm{ng} / \mathrm{mL}$ and not in $\mathrm{ng} / \mathrm{dL}$ as done by researchers of other Indian studies. ${ }^{20-22}$

When fT4 is within normal limits but TSH level is persistently above the normal limit, a biochemical diagnosis of subclinical hypothyroidism can be confirmed. TSH levels within normal range of laboratory do not always mean the

Table 5 Comparison of reference ranges for thyrotropin and fT4 during early pregnancy

\begin{tabular}{|c|c|c|c|c|c|c|c|}
\hline \multirow[t]{2}{*}{ Author(s) ${ }^{\text {Ref }}$, country } & \multirow[t]{2}{*}{$n$} & \multirow{2}{*}{$\begin{array}{l}\text { Gestation } \\
\text { week }\end{array}$} & \multirow[t]{2}{*}{ Assay used } & \multicolumn{2}{|c|}{$\mathrm{TSH}, \mathrm{mIU} / \mathrm{L}$} & \multicolumn{2}{|c|}{ fT4, ng/dL (pmol/L) } \\
\hline & & & & Median & 2.5th-97.5th & Median & 2.5th-97.5th \\
\hline \multicolumn{8}{|l|}{ Studies done outside India } \\
\hline Bestwick et al, ${ }^{9}$ Italy & 5,505 & $<16$ & CL (Auto DELFIA ${ }^{a}$ ) & 1.07 & $0.04-3.19$ & $0.7(9.3)$ & $0.6-0.9(7.4-12.2)$ \\
\hline Bestwick et al, ${ }^{9}$ UK & 16,334 & $<16$ & $\mathrm{CL}$ (ADVIA Centaur ${ }^{\mathrm{b}}$ ) & 1.11 & $0.06-3.50$ & $1.1(13.9)$ & $0.8-1.4(10.9-17.9)$ \\
\hline Karakosta et al, ${ }^{26}$ Greece & 141 & $<13$ & CL (IMMULITE 2000') & 1.02 & $0.05-2.53$ & $1.24(15.96)^{f}$ & $0.96-1.60(12.36-20.59)^{f}$ \\
\hline Li et al, ${ }^{11}$ China & 1,024 & $4-12$ & CobasElesys $601^{d}$ & 1.66 & $0.14-4.87$ & $1.2(15.84)$ & $1.0-1.6(12.35-20.71)$ \\
\hline Zhang et al, ${ }^{27}$ China & 132 & $1-12$ & $\mathrm{CL}$ (Centaur $\mathrm{CP}^{\mathrm{b}}$ ) & NR & $0.02-3.78$ & NR & $1.08-2.058(13.93-26.49)$ \\
\hline \multicolumn{8}{|l|}{ Studies done in India } \\
\hline Maji et al, ${ }^{20}$ India & 125 & $<13$ & ELISA (Acubind ${ }^{\mathrm{e}}$ ) & 1.8 & $0.25-3.35$ & $1.4(18.1)$ & $0.64-2.0(8.3-25.8)$ \\
\hline Mankar et al, ${ }^{21}$ India & 50 & $8-10$ & CL Immunoassay (NR) & NR & $0.24-4.17^{\mathrm{a}}$ & NR & $01-2.2^{9}(12.9-28.9)$ \\
\hline Rajput et al, ${ }^{19}$ India & 301 & $\leq 12$ & $\begin{array}{l}\text { ECL (ADVIA } \\
\left.\text { Centaur } C P^{\mathrm{b}}\right)^{\mathrm{h}}\end{array}$ & 1.40 & $0.37-3.69$ & $125(1608.75)$ & $88-178^{i}(1,132.6-2,290.86)$ \\
\hline Pramanik et al, ${ }^{22}$ India & 80 & NR & CL (IMMULITE $1000^{\mathrm{b}}$ ) & NR & $0.19-4.34$ & NR & $0.88-1.32(11.33-16.99)$ \\
\hline Our study, India & 341 & $\leq 14$ & $\begin{array}{l}\mathrm{CL}(\mathrm{ADVIA} \\
\text { Centaur } \mathrm{XP}^{\mathrm{b}} \text { ) }\end{array}$ & 1.820 & $0.25-4.97$ & $1.12(14.4)$ & $0.79-1.46(10.2-18.8)$ \\
\hline
\end{tabular}

Abbreviations: CL, chemiluminescence; ECL, electrochemiluminescence; ELISA, enzyme-linked immunosorbent assay; fT4, free thyroxine; NR, not reported; TSH, thyroid stimulating hormone.

$1 \mathrm{pmol} / \mathrm{L}=0.078 \mathrm{ng} / \mathrm{dL} ; 1 \mathrm{kIU} / \mathrm{L}=1 \mathrm{mIU} / \mathrm{L}$.

aPerkinElmer Life and Analytical Sciences.

bSiemens Healthcare Diagnostics.

'Ortho Clinical Diagnostics.

${ }^{\mathrm{d}}$ Roche Diagnostics.

${ }^{\mathrm{e}}$ Monobind Inc.

$f_{5 \text { th }}$ and 95 th centiles were used to determine the reference range.

IfT4 values were calculated in 139 women.

hSeems like an error in the cited study as ADVIA Centaur CP uses CL and not, ECL.

'Mentioned as $0.88-1.78 \mathrm{ng} / \mathrm{mL}$ in the report. 
individual has normal thyroid function. ${ }^{7}$ The TSH value may be outside the individual reference range. However, it is impractical to take several samples and measure individual reference range for each patient. Laboratory-specific reference range is preferred. It is not difficult to calculate laboratory-specific reference range. Every hospital where perinatal care is provided can collaborate with its clinical biochemistry department and conduct a study to determine their own laboratory-specific GRIs for TSH and fT4.

Andersen et $\mathrm{al}^{23}$ and Laurberg et al ${ }^{1}$ report that the use of uniform reference range for TSH and fT4 in early pregnancy may be too simple and can lead to frequent misclassification and incorrect use of therapy. They suggest the use of a reference range stratified by the week of pregnancy because of the dynamic physiological changes seen over weeks. We observed no significant difference in the TSH and fT4 reference ranges among women in early or women in late first trimester. Khalil et al ${ }^{24}$ had also found no difference in the 4 to 6 weeks and 7 to 12 weeks gestation groups.

TSH ranges can vary slightly depending on the method of analysis used. This variability can be reduced by using MoM values. ${ }^{13}$ MoM is often used for screening test results. Computer software is available that can convert marker levels of Down syndrome or neural tube defects to MoM values. Similar software can be used to calculate MoM values for TSH and fT4 levels. Data from approximately 100 patients would be sufficient. ${ }^{9}$ We have used data from 341 patients to determine the MoM values.

An individual value is divided by the population median and the resulting value is not influenced by the method of assay used. Reporting the MoM value along with the centile, it corresponds to, does not put a woman into the abnormal category that can happen when only the reference range is used. ${ }^{9}$ MoM values also take into account certain factors such as gestational age and maternal weight that can have a relationship with TSH and fT4 values. ${ }^{9}$

Considering obesity is increasing in many populations, it may be an important finding that maternal weight correlated with TSH MoM values $(p=0.027, r=0.120)$. Bestwick et al ${ }^{9}$ had found that for every $10 \mathrm{~kg}$ increase in weight, there was $0.025 \mathrm{MoM}$ increase in TSH MoM values and $0.009 \mathrm{MoM}$ decrease in fT4 MoM values. In contrast, we found no significant correlation between maternal weight and fT4 MoM values $(p=0.749, r=-0.017)$.

The 1st to 99th percentiles of TSH and fT4 MoM values in our study were 0.03 to 4.09 and 0.66 to 1.39 , respectively. In a study by Kianpour et al, ${ }^{25}$ among pregnant Iranian women with gestational age $\leq 14$ weeks, the corresponding values were 0.06 to 4.62 and 9.00 to 18.02 , respectively. In the study by Bestwick et al, ${ }^{9}$ among pregnant women (gestational age less than 16 weeks) from United Kingdom, the 1st to 99th percentiles of TSH and fT 4 MoM values were 0.02 to 4.13 and 0.75 to 1.38 , respectively. Among those from Italy, corresponding values were 0.01 to 3.93 and 0.76 to 1.46 , respectively. Both our TSH and fT4 MoM results match those from the two populations studied by Bestwick et al, ${ }^{9}$ whereas only our TSH MoM values match those from the study by Kianpour et al. ${ }^{25}$ The first-trimester-specific reference interval for serum fT4 is similar in both our study and that by Kianpour et al, but the fT 4 MoM values are grossly different. A careful look at the fT4 MoM values published by them in a 2019 issue of Hormone and Metabolic Research suggests that there might have been some error as the numerical values of MoM are exactly the same as the individual centile values for fT4. ${ }^{25}$

To the best of our knowledge, ours is the largest Indian study of women in their first trimester that determines the laboratory-specific GRIs for TSH and fT4. It is also probably the first one in South East Asia to determine the MoM values for TSH and fT4 during the first trimester. Another strength of our study was the measurement of anti-TPO, urine iodide, and detection of multiple gestations through ultrasound scanning. It helped in a clearer definition of the normal population for reference ranges. We could also have attempted to determine the GRIs for the second and third trimester using this sample population. Though our sample size of 341 pregnant women in their first trimester is perhaps the largest in India, a larger sample size could have provided more accurate reference intervals.

To obviate the slightly different, although overlapping, reference ranges of various commercially available assays, we have used the MoMs. This may allow other laboratories to use our specific MoM thresholds to their centers once they have established their own first trimester-specific medians. Further research is needed to validate the extrapolation of our specific MoM values to other centers.

\section{Conclusion}

In this study, GRIs of serum TSH and fT4 were determined for singleton pregnant Indian women with anti-TPO less than 60 $\mathrm{kIU} / \mathrm{L}$ and adequate level of iodine. The GRIs determined in our study are different from that of ATA and the GRIs determined by other studies (-Table 5). Our laboratoryspecific reference ranges may be used for the pregnant women in Chhattisgarh. Once first-trimester median values are obtained by a laboratory, it will also be able to use our MoM values as cutoffs to obviate differences in the assay methods. This can aid accurate detection of thyroid disorders during pregnancy in a specific population.

\section{Authors' Disclosure Statement \\ No competing financial or personal interest.}

\section{Authorship Participation}

R.N. was involved in concept and design of work, sample analysis, and wrote first draft of the manuscript. P.K.N. was involved in design of work, acquisition, and analysis of data. S.P. was involved in interpretation of data and drafting of manuscript. E.M. was involved in sample analysis and revising the work critically, and S.A. was involved in acquisition and interpretation of data and revising the work critically. All authors have reviewed and approved of the manuscript prior to submission. This manuscript has been submitted solely to this journal and is not published in press or submitted elsewhere. 


\section{Ethical Approval}

Approval taken from Institute Ethics Committee, AIIMS Raipur AIIMSRPR/IEC/2016/019.

\section{Funding Statement}

The authors would like to thank Chhattisgarh Council of Science and Technology for sanctioning grants vide council letter no. 172/CCOST/218.

\section{Conflict of Interest}

Dr. Nanda reports grants from Chhattisgarh Council of Science and Technology for sanctioning grants vide council letter no. $172 /$ CCOST/218, during the conduct of the study.

\section{Acknowledgments}

The authors would like to thank Dr. Natasha Das and the team of Hazlo Consultancy Pvt Ltd, Delhi, India (www. hazloconsultancy.com), for the support provided in statistical analysis, in writing multiple drafts of the manuscript in consultation with the authors, in preparing the final manuscript along with the tables and figures, in language editing of the final draft, and in formatting the manuscript as per the journal's specific requirements.

\section{References}

1 Laurberg P, Andersen SL, Hindersson P, Nohr EA, Olsen J. Dynamics and predictors of serum TSH and fT4 reference limits in early pregnancy: a study within the Danish National Birth Cohort. J Clin Endocrinol Metab 2016;101(06):2484-2492

2 Wang G, Zhang G. The diverse upper reference limits of serum thyroid-stimulating hormone on the same platform for pregnant women in China. Lab Med 2020;51(04):416-422

3 Sun R, Xia J. The reference intervals of thyroid hormones for pregnant women in Zhejiang Province. Lab Med 2017;49(01): 5-10

4 De Groot L, Abalovich M, Alexander EK, et al. Management of thyroid dysfunction during pregnancy and postpartum: an Endocrine Society clinical practice guideline. J Clin Endocrinol Metab 2012;97(08):2543-2565

5 Lazarus J, Brown RS, Daumerie C, Hubalewska-Dydejczyk A, Negro R, Vaidya B. 2014 European thyroid association guidelines for the management of subclinical hypothyroidism in pregnancy and in children. Eur Thyroid J 2014;3(02):76-94

6 Stagnaro-Green A, Abalovich M, Alexander E, et al; American Thyroid Association Taskforce on Thyroid Disease During Pregnancy and Postpartum. Guidelines of the American Thyroid Association for the diagnosis and management of thyroid disease during pregnancy and postpartum. Thyroid 2011;21(10): 1081-1125

7 Khadilkar S. Thyroid-stimulating hormone values in pregnancy: cutoff controversy continues? J Obstet Gynaecol India 2019;69 (05):389-394

8 Korevaar TIM. The upper limit for TSH during pregnancy: why we should stop using fixed limits of 2.5 or $3.0 \mathrm{mU} / \mathrm{l}$. Thyroid Res 2018; 11:5. Doi: 10.1186/s13044-018-0048-7

9 Bestwick JP, John R, Maina A, et al. Thyroid stimulating hormone and free thyroxine in pregnancy: expressing concentrations as multiples of the median (MoMs). Clin Chim Acta 2014;430:33-37
10 Springer D, Jiskra J, Limanova Z, Zima T, Potlukova E. Thyroid in pregnancy: from physiology to screening. Crit Rev Clin Lab Sci 2017;54(02):102-116

11 Li C, Shan Z, Mao J, et al. Assessment of thyroid function during first-trimester pregnancy: what is the rational upper limit of serum TSH during the first trimester in Chinese pregnant women? J Clin Endocrinol Metab 2014;99(01):73-79

12 Hubalewska-Dydejczyk A, Trofimiuk-Müldner M. The development of guidelines for management of thyroid diseases in pregnancy - current status. Thyroid Res 2015;8(01):A1-A3

13 Alexander EK, Pearce EN, Brent GA, et al. 2017 Guidelines of the American Thyroid Association for the diagnosis and management of thyroid disease during pregnancy and the postpartum. Thyroid 2017;27(03):315-389

14 Cunningham FG, Leveno KJ, Bloom SL, et al , Eds. Chapter 9: Prenatal Care. In: Williams Obstetrics. 24th ed. New York, United States: McGraw-Hill Education; 2014:167-193

15 Kalra S, Agarwal S, Aggarwal R, Ranabir S. Trimester-specific thyroid-stimulating hormone: an Indian perspective. Indian J Endocrinol Metab 2018;22(01):1-4

16 Medici M, Korevaar TIM, Visser WE, Visser TJ, Peeters RP. Thyroid function in pregnancy: what is normal? Clin Chem 2015;61(05): 704-713

17 International Council for Control of Iodine Deficiency Disorders, UNICEF, World Health Organization. Assessment of Iodine Deficiency Disorders and Monitoring Their Elimination: A Guide for Programme Managers. Geneva, Switzerland: World Health Organization; 2007

18 Korevaar TIM. Levothyroxine overtreatment during pregnancy is associated with a higher risk of adverse child mental health outcomes. Clin Thyroidol 2020;32(01):20-23

19 Rajput R, Singh B, Goel V, Verma A, Seth S, Nanda S. Trimesterspecific reference interval for thyroid hormones during pregnancy at a Tertiary Care Hospital in Haryana, India. Indian J Endocrinol Metab 2016;20(06):810-815

20 Maji R, Nath S, Lahiri S, Saha Das M, Bhattacharyya AR, Das HN. Establishment of trimester-specific reference intervals of serum TSH \& fT4 in a pregnant Indian population at North Kolkata. Indian J Clin Biochem 2014;29(02):167-173

21 Mankar J, Sahasrabuddhe A, Pitale S. Trimester specific ranges for thyroid hormones in normal pregnancy. Thyroid Res Pract 2016; 13(03):106-109

22 Pramanik S, Mukhopadhyay P, Bhattacharjee K, et al. Trimesterspecific reference intervals for thyroid function parameters in Indian pregnant women during final phase of transition to iodine sufficiency. Indian J Endocrinol Metab 2020;24(02):160-164

23 Andersen SL, Andersen S, Carlé A, et al. Pregnancy week-specific reference ranges for thyrotropin and free thyroxine in the North Denmark region pregnancy cohort. Thyroid 2019;29(03):430-438

24 Khalil AB, Salih BT, Chinengo O, Bardies MRD, Turner A, Abdel Wareth LO. Trimester specific reference ranges for serum TSH and free T4 among United Arab Emirates pregnant women. Pract Lab Med 2018;12:e00098. Doi: 10.1016/j.plabm.2018.e00098

25 Kianpour M, Aminorroaya A, Amini M, et al. Reference intervals for thyroid hormones during the first trimester of gestation: a report from an area with a sufficient iodine level. Horm Metab Res 2019;51(03):165-171

26 Karakosta P, Chatzi L, Bagkeris E, et al. First- and second-trimester reference intervals for thyroid hormones during pregnancy in "rhea" mother-child cohort, Crete, Greece. J Thyroid Res 2011; 2011:490783. Doi: 10.4061/2011/490783

27 Zhang D, Cai K, Wang G, et al. Trimester-specific reference ranges for thyroid hormones in pregnant women. Medicine (Baltimore) 2019;98(04):e14245. Doi: 10.1097/MD.0000000000014245 